\title{
' INVENTARISASI JENIS-JENIS SERANGGA ORDO ORTHOPTERA PADA TANAMAN JAGUNG DI DESA KESIMAN-DENPASAR
}

\section{INVENTARIZATION OF INSECT SPECIES FROM ORTHOPTERA ON Zea Mays PLANT AT KESIMAN VILLAGE- DENPASAR}

\author{
I Gusti Putu Diah Purnama Sari ${ }^{1}$, Ni Made Suartini ${ }^{2}$, I Ketut Muksin ${ }^{3}$ \\ 1. Mahasiswa Progran Studi Biologi FMIPA Universitas Udayana \\ 2,3. Progran Studi Biologi FMIPA Universitas Udayana \\ email: purnamatama22@yahoo.com
}

\section{INTISARI}

Penelitian ini bertujuan untuk mengetahui jenis-jenis serangga Ordo Orthoptera dan perannya terhadap tanaman jagung di Desa Kesiman, Denpasar. Penelitian dilakukan dari bulan Desember 2015 - Februari 2016 dengan metode sweeping pada tiap petak pertanaman jagung dengan luas masing-masing $10 \mathrm{~m}$ x $25 \mathrm{~m}$. Pengambilan sampel dilakukan dari fase Ve sampai fase matang fisiologis sebanyak tiga kali pada setiap fase. Rentang waktu pengambilan sampel mulai dari pukul 07.00 sampai 10.00 WITA. Pengambilan sampel pada masing-masing petak dilakukan selama 15 menit/250m². Setelah teridentifikasi, data kuantitaf dianalisis dengan rumus untuk kepadatan menurut Krebs (1989). Ordo Orthoptera yang ditemukan adalah sebanyak 242 individu yang mencakup 8 famili dengan 25 jenis yaitu Atractomorpha sp., Orchelimum sp., Phlaeoba sp., Gastrimargus sp., Urnisiella sp., Metaleptea brevicornis, Xenocatantops sp., Scudderia sp., Calolampra sp., Eritettix sp., Platyzoteria sp., Conocephalus strictus, Morabine sp., Acrida sp., Tenodera sp., Stagmomantis sp., Blattela sp., Periplaneta sp., Tettigidea sp. 1, Tettigidea sp. 2, Tettigidea lateralis, Mantis sp., Gryllus sp., Anaxipha exigua, dan jenis x. Ordo Orthoptera yang ditemukan berperan sebagai omnivora, herbivora, dan predator. Famili yang berperan sebagai omnivora adalah Famili Blattidae dan Grillidae, famili yang berperan sebagai herbivora adalah Pyrgomorphidae, Acrididae, Tettigonidae, Eumastacidae, dan Tetrigidae, sedangkan famili yang berperan sebagai predator adalah Famili Mantidae.

Katakunci : jagung, orthoptera, jenis, peran.

\section{ABSTRACT}

In Indonesian national economics, maize is a second food source after rice. The production of maize in some aspect is affected by the presence of insect particularly Orthopteran Order. The information of advantage and disadvantage of insects is useful for farmers. This research aimed to determine the species of Orthopteran and it is role to maize plant in the Village Kesiman, Denpasar. This research was conducted from December 2015 to February 2016. Insect was collected using sweeping net accordingly in each plot of maize plants. The plot was square form with the size of $10 \mathrm{~m} \times 25 \mathrm{~m}$. The sample was collected from the maize plant in the Ve phase until physiological maturation phase. in each phase, from 07.00 am until 10.00 am Bali time. Sample was collected for 15 minutes per plot and repeated three times. The insects collected was identified, and the insect density was predicted following Krebs (1989). As many as 242 individual insect which belong to Orthopteran Order was collected. Those belong to 8 families and 25 species. The species were Atractomorpha sp., Orchelimum sp., Phlaeoba sp., Gastrimargus sp., Urnisiella sp., Metaleptea brevicornis, Xenocatantops sp., Scudderia sp., Calolampra sp., Eritettix sp., Platyzoteria sp., Conocephalus strictus, Morabine sp., Acrida sp., Tenodera sp., Stagmomantis sp., Blattela sp., Periplaneta sp., Tettigidea lateralis, Mantis sp., Gryllus sp., and Anaxipha exigua, Tettigidea sp. 2, Tettigidea sp. 1, and unidentified (species x). Families that act as omnivores are Family Blattidae and Grillidae, families that act as herbivores are Pyrgomorphidae, Acrididae, Tettigonidae, Eumastacidae, and Tetrigidae, while families that act as predators are Mantidae.

Keyword : maize, orthopteran, insect species, insect role.

\section{PENDAHULUAN}

Jagung (Zea mays L.) merupakan komoditas pangan yang sangat diminati oleh masyarakat dunia. Di Indonesia, jagung menempati posisi penting dalam perekonomian nasional sebagai sumber karbohidrat kedua setelah beras (Akil dan Hadijah, 2007). Produksi jagung salah satunya dipengaruhi oleh serangan organisme pengganggu tanaman (OPT) yang merupakan kendala produksi (Surtikanti, 2011).

Serangga yang dapat menyerang tanaman jagung di Indonesia, ditemukan lebih dari 50 jenis (Baco dan Tandiabang, 1998), salah satunya adalah serangga dari Ordo Orthoptera. Menurut penelitian yang dilakukan Leatemia dan Rumthe (2011), intensitas kerusakan perkebunan jagung yang diakibatkan oleh Ordo Orthoptera mencapai 25,64\% (kategori kerusakan sedang) sehingga ordo ini tergolong serangga yang rakus. Namun tidak semua serangga dari Ordo Orthoptera berperan sebagai hama. Beberapa diantaranya berperan sebagai omnivora (Famili Gryllidae dan Blattidea) dan sebagai predator (Famili Mantidae) yang dapat dijadikan sebagai musuh alami dari hama tanaman (Baldi dan Kisbenedek, 1997).sedangkan serangga Orthoptera pada Famili Acrididae, Pyrgomorphidae, Eumastacidae, Tertigidae, dan Tettigonidae berperan sebagai hama yang sangat merugikan bagi petani (Micheneau et al., 2010).

Serangga hama dapat menyerang pada seluruh fase pertumbuhan, baik vegetatif maupun generatif (Susniahti dkk., 2005). Serangga hama tersebut dapat mempengaruhi kualitas (mutu) dan kuantitas (jumlah) pertanaman jagung. Kerusakan kuantitatif mengarah pada berkurangnya jumlah jagung yang dapat dipanen, sedangkan kerusakan kualitatif mengarah pada menurunnya mutu dari tanaman jagung misalnya kerasnya biji, warna butir tidak seragam, dan adanya butir yang pecah (Winarno, 1997). Berdasarkan hal di atas, 
maka perlu dilakukan penelitian mengenai jenis-jenis serangga yang termasuk dalam Ordo Orthoptera dan perannya terhadap tanaman jagung.

\section{MATERI DAN METODE}

Penelitian ini dilaksanakan di perkebunan jagung di Desa Kesiman-Denpasar dari Bulan Desember 2015 hingga Februari 2016. Pengambilan sampel dilakukan pada satu lokasi dengan dua petak pertanaman jagung berukuran $10 \mathrm{~m}$ x $25 \mathrm{~m}$ yang masing-masing terdapat 20 bedeng tanaman jagung dengan ukuran $5 \mathrm{~m} \times 2 \mathrm{~m}$, dan jarak antar bedeng $35 \mathrm{~cm}$. Pengambilan sampel dilakukan selama $15 \mathrm{menit} / 250 \mathrm{~m}^{2}$. Metode yang digunakan untuk pengambilan sampel adalah metode sweeping (sapuan) dengan insect/aerial net atau jaring serangga berdiameter $\pm 30 \mathrm{~cm}$ dengan mengayunkan membentuk angka delapan. Urutan petak yang diambil sampel dilakukan secara undian. Pengambilan sampel dilakukan pada masing-masing fase yaitu (1) fase Ve/emergence yaitu daun pertama muncul di atas tanah, (2) fase V3-V5 yaitu jumlah daun terbuka 3-5 helai, (3) fase V6-V10 yaitu jumlah daun terbuka 6-10 helai, (4) fase V11-V16 yaitu jumlah daun terbuka 11-16 helai, (5) fase tasseling yaitu keluar malai, (6) fase silking yaitu keluar rambut, (7) fase blister yaitu pembentukan biji dan (8) fase matang fisiologis. Masing-masing fase diambil sebanyak 3 kali ulangan. Suhu dan kelembaban diukur setiap pengambilan sampel menggunakan thermohygrometer.

Rumus yang digunakan untuk data kuantitaf yang dianalisis adalah rumus untuk kepadatan menurut Krebs (1989) yaitu:

$$
\mathrm{K}=\frac{\mathrm{Ni}}{\mathrm{A}}
$$

$\mathrm{K}=$ kepadatan individu (ind $\left./ \mathrm{m}^{2}\right)$

$\mathrm{Ni}=$ jumlah individu

$\mathrm{A}=$ luas area

\section{HASIL}

Ordo Orthoptera yang ditemukan berjumlah 242 individu yaitu 153 individu pada petak satu dan 89 individu pada petak dua. Ordo Orthoptera yang ditemukan terdiri atas 8 famili, 25 jenis dan peran masing-masing famili tercantum pada Tabel 1.

\begin{tabular}{|c|c|c|c|c|}
\hline \multirow[t]{2}{*}{ Famili } & \multirow[t]{2}{*}{ Jenis } & \multicolumn{2}{|c|}{ Kepadatan $\left(\operatorname{Ind} / 250 \mathrm{~m}^{2}\right)$} & \multirow[t]{2}{*}{ Peran } \\
\hline & & Petak 1 & Petak 2 & \\
\hline \multirow[t]{3}{*}{ Pyrgomorphidae } & Atractomorpha sp. & 8,0 & 6,0 & Herbivora \\
\hline & Acrida $\mathrm{sp}$ & 1,3 & 1,0 & Herbivora \\
\hline & jenis $\mathrm{x}$ & 0,7 & 0,3 & Herbivora \\
\hline \multirow[t]{6}{*}{ Acrididae } & Phlaeoba sp. & 4,7 & 5,7 & Herbivora \\
\hline & Gastrimargus sp. & 3,7 & 0,3 & Herbivora \\
\hline & Urnisiella sp. & 3,7 & 0 & Herbivora \\
\hline & Metaleptea brevicornis & 3,0 & 1,7 & Herbivora \\
\hline & Xenocatantops sp. & 2,7 & 2,3 & Herbivora \\
\hline & Eritettix sp. & 1,3 & 2,0 & Herbivora \\
\hline \multirow[t]{3}{*}{ Tettigonidae } & Orchelimum sp. & 6,3 & 1,0 & Herbivora \\
\hline & Scudderia sp. & 2,3 & 2,0 & Herbivora \\
\hline & Conocephalus strictus & 1,4 & 0,3 & Herbivora \\
\hline \multirow[t]{4}{*}{ Blattidae } & Platyzoteria sp. & 1,7 & 0 & Omnivora \\
\hline & Calolampra sp. & 1,4 & 2,0 & Omnivora \\
\hline & Periplaneta sp. & 0,7 & 0,3 & Omnivora \\
\hline & Blattela sp. & 0,7 & 0,7 & Omnivora \\
\hline \multirow[t]{3}{*}{ Mantidae } & Stagmomantis sp. & 1,0 & 0 & Predator \\
\hline & Mantis sp. & 0,3 & 0 & Predator \\
\hline & Tenodera sp. & 0,7 & 1,0 & Predator \\
\hline Eumastacidae & Morabine sp. & 1,3 & 0 & Herbivora \\
\hline \multirow{3}{*}{ Tetrigidae } & Tettigidea sp. 1 & 0,3 & 0 & Herbivora \\
\hline & Tettigidea sp. 2 & 0,7 & 0 & Herbivora \\
\hline & Tettigidea lateralis & 0,3 & 0,3 & Herbivora \\
\hline \multirow[t]{2}{*}{ Gryllidae } & Gryllus sp. & 0 & 0,3 & Omnivora \\
\hline & Anaxipha exigua. & 0 & 0,3 & Omnivora \\
\hline
\end{tabular}

Tabel 1. Famili, jenis, rata-rata kepadatan dan peran dari Ordo Orthoptera.

Ordo Orthoptera yang ditemukan memiliki tiga peran terhadap tanaman jagung yaitu sebagai herbivora, omnivora, dan predator. Ordo Orthoptera yang banyak ditemukan berperan sebagai herbivora yaitu Pyrgomorphidae, Acrididae, Tettigonidae, Eumastacidae, dan Tetrigidae yang merupakan 5 famili Orthoptera dari jumlah total 8 famili yang ditemukan. Ordo Orthoptera yang berperan sebagai omnivora adalah Famili Blattidae dan Gryllidae, sedangkan peran sebagai predator hanya ditemukan dari Famili Mantidae. Penentuan peran pada jenis serangga yang ditemukan dilihat secara mengelompok melalui famili dari jenis serangga tersebut.

Perbandingan jumlah Ordo Orthoptera yang ditemukan pada petak satu dan dua menunjukan bahwa secara umum petak satu lebih banyak ditemukan Ordo Orthoptera dibandingkan dengan petak dua (Gambar 1). 


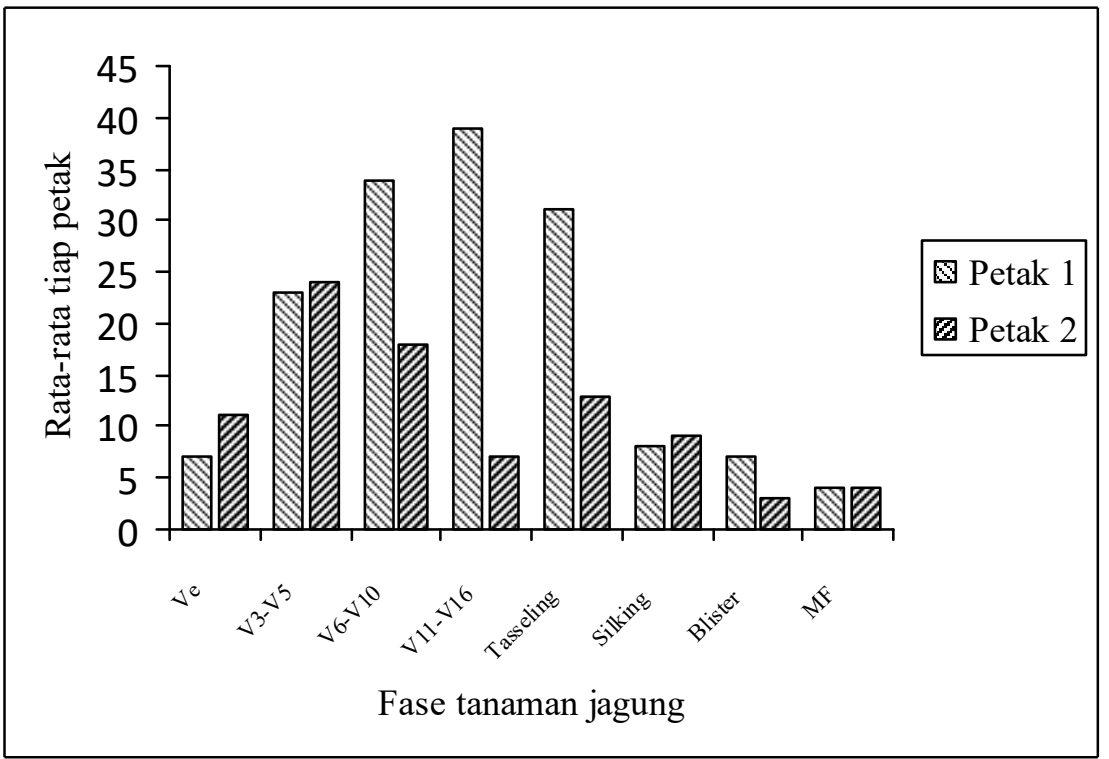

Gambar 1. Perbandingan rata-rata Ordo Orthoptera pada petak satu dan petak dua per fase

Jumlah individu yang ditemukan pada petak satu dan dua dirata-ratakan sehingga menunjukan perbandingan jumlah individu antara tiap fase tanaman jagung memiliki bentuk diagram yang fluktuatif dengan fase yang paling tinggi adalah fase V6-V10 dan fase yang paling rendah adalah fase matang fisiologis (MF) (Gambar 2).

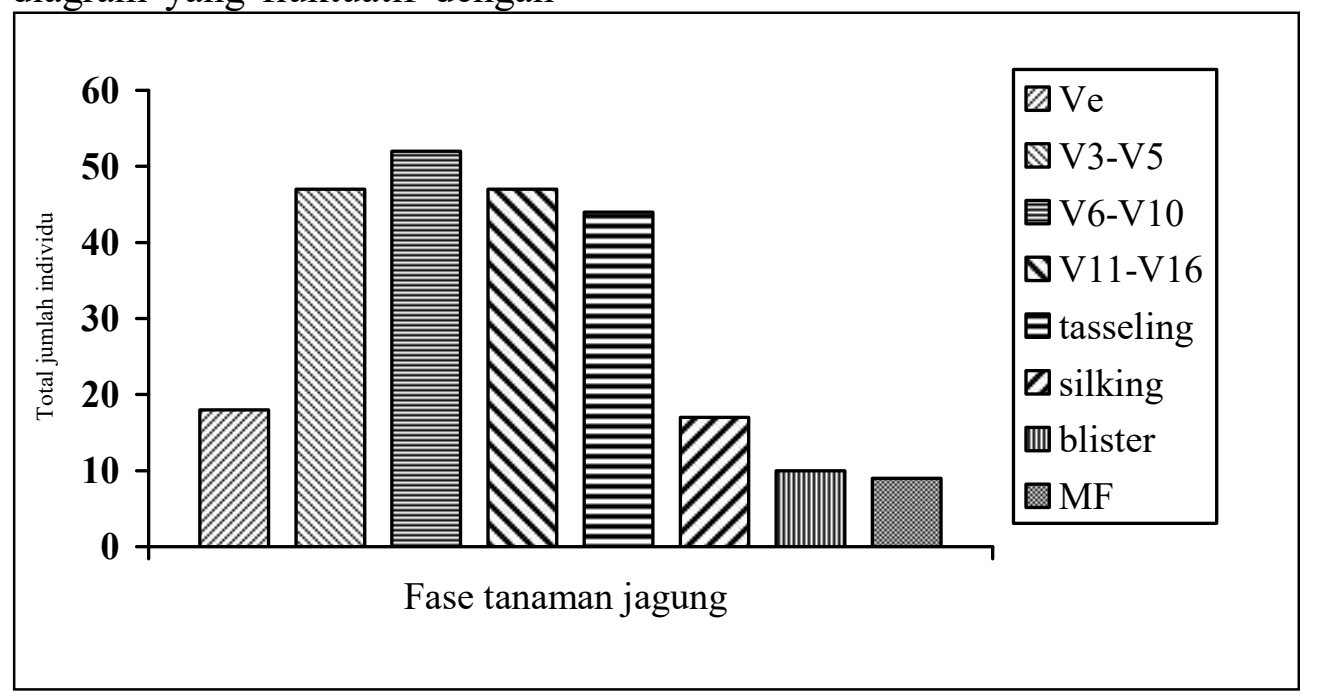

Gambar 2. Rata-rata jumlah Ordo Orthoptera yang ditemukan tiap fase

Tabel 2. Suhu dan kelembaban setiap ulangan per fase tanaman jagung.

\begin{tabular}{|c|c|c|c|c|c|c|c|c|}
\hline \multirow{2}{*}{$\begin{array}{c}\text { Fase } \\
\text { tanaman } \\
\text { jagung }\end{array}$} & \multicolumn{3}{|c|}{ Suhu $\left({ }^{\circ} \mathrm{C}\right)$} & \multirow{2}{*}{$\begin{array}{c}\text { Rata- } \\
\text { rata } \\
\text { suhu } \\
\left({ }^{\circ} \mathrm{C}\right)\end{array}$} & \multicolumn{3}{|c|}{ Kelembaban (\%) } & \multirow{2}{*}{$\begin{array}{c}\text { Rata-rata } \\
\text { kelembaban } \\
(\%)\end{array}$} \\
\hline & 1 & 2 & 3 & & 1 & 2 & 3 & \\
\hline $\mathrm{VE}$ & 31 & 31,9 & 32,8 & 31,9 & 68 & 65 & 65 & 66 \\
\hline V3-V5 & 33 & 27 & 30 & 30 & 63 & 75 & 68 & 68,7 \\
\hline V6-V10 & 30 & 26,1 & 29,2 & 28,4 & 68 & 75 & 75 & 72,7 \\
\hline V11-V16 & 28 & 19,8 & 30 & 25,9 & 78 & 80 & 68 & 75,3 \\
\hline Taselling & 31 & 29 & 30 & 30 & 68 & 70 & 67 & 68,3 \\
\hline Silking & 29,2 & 32 & 31 & 30,7 & 75 & 63 & 68 & 68,7 \\
\hline Blister & 30 & 31,9 & 29 & 30,3 & 68 & 65 & 73 & 68,7 \\
\hline $\mathrm{MF}$ & 31 & 31 & 30 & 30,7 & 68 & 65 & 67 & 66,7 \\
\hline Rata-rata & 30,4 & 28,6 & 30,3 & 29,8 & 69,5 & 69,8 & 68,9 & 69,4 \\
\hline
\end{tabular}

\section{PEMBAHASAN}

Jenis yang paling banyak ditemukan pada petak satu dan petak dua adalah Atractomorpha sp. Tipe mulut dari Atractomorpha sp. adalah penggigit-pengunyah (Hadi dan Aminah, 2012) sehingga berperan sebagai hama yang menurunkan nilai kuantitas dan kualitas dari tanaman jagung. Atractomorpha sp. mampu menyesuaikan diri terhadap suhu lingkungan yang tidak menguntungkan baginya sehingga mudah untuk bertahan pada lingkungan tersebut. Jenis ini dapat melakukan polimorfisme yaitu kemampuan untuk merubah warna tubuh dari hijau menjadi coklat ketika suhu lingkungan semakin tinggi.
Jenis yang sedikit ditemukan adalah Tettigidea $\mathrm{sp}$ 2., Tettigidea lateralis, Mantis sp., Gastrimargus sp., Periplaneta sp., Conocephalus strictus, Gryllus sp., Anaxipha exigua, dan jenis x. Kedelapan jenis tersebut masuk dalam Famili Tetrigidae, Mantidae, Acrididae, Blattidae, Tettigonidae, Gryllidae, dan Eumastacidae. Serangga-serangga tersebut secara umum memiliki ukuran yang kecil yaitu kurang dari $20 \mathrm{~mm}$ (Borror et al., 1989), suka berada pada bagian tanaman yang lembab, beberapa ada yang memakan tanaman yang sudah layu (Hastuti, 2012.), memiliki cakupan mobilitas yang tinggi untuk mencari mangsa di suatu ekosistem seperti Mantidae (Gulo, dkk., 2014), kepekaannya terhadap 
gangguan yang cukup tinggi (Foltz and Frank, 1997), dan waktu aktif serangga seperti Famili Gryllidae yang aktif pada malam hari dan umumnya hidup di permukaan tanah atau di tempat yang lembab (Semangun, 1991).

Omnivora adalah serangga pemakan hewan dan tumbuhan. Terkait dengan tanaman jagung, serangga ini akan memakan serasah yang terdapat dibawah tanaman jagung sehingga secara tidak langsung dapat menyuburkan tanah (Borror et al., 1992). Serangga Orthoptera yang berperan sebagai omnivora lebih sedikit dibandingkan herbivora dan predator karena omnivora yang ditemukan mobilitasnya lebih banyak bersembunyi dibawah tangkai daun dan tongkol atau di permukaan tanah (Erawati, dkk., 2004). Omnivora yang ditemukan adalah Famili Blattidae dan Grillydae.

Serangga herbivora sebagian besar adalah serangga hama yang dapat menimbulkan kerugian ekonomi bagi petani karena memakan tumbuh-tumbuhan (Hill, 1997). Distribusi dan kelimpahan serangga herbivora dipengaruhi oleh kualitas tanaman yang di makan (Awmack dan Leather, 2002). Jumlah Orthoptera sebagai herbivora yang ditemukan lebih banyak dibandingkan predator dan omnivora karena tanaman jagung yang menjadi makannya melimpah di wilayah tersebut.

Predator adalah serangga pemakan serangga lain yang dapat menjadi biokontrol alami (musuh alami) pada ekosistem (Buchori dan Sahari, 2000). Jenis predator yang ditemukan adalah Famili Mantidae yang lebih sedikit dibandingkan dengan herbivora karena memiliki mobilitas yang cukup luas untuk mencari makanannya Famili Mantidae memiliki peran sebagai predator sehingga memiliki mobilitas yang tinggi untuk mencari mangsa di suatu ekosistem (Gulo dkk., 2014) dan peka terhadap gangguan di sekitarnya (Kartasapoetra, 1993). Orthoptera yang berperan sebagai predator tidak merugikan petani.

Jumlah jenis yang ditemukan pada petak satu lebih banyak dibandingkan dengan petak dua karena faktor vegetasi lingkungan sekitar petak satu lebih beragam yang dikelilingi oleh beberapa tanaman rerumputan (Poaceae) misalnya tanaman padi, tanaman tebu, dan rumput alang-alang. Selain itu juga terdapat tanaman lainnya, misalnya tanaman bawang dan tanaman ratna. Pada petak dua dikelilingi oleh tanaman pisang saja. Jenis tanaman yang lebih beragam di sekitar petak satu menyebabkan jumlah Ordo Orthoptera yang ditemukan lebih banyak karena ketersediaan makanannya yang lebih melimpah. Menurut Pabbage dkk. (2000), tanaman yang dominan disukai oleh Orthoptera adalah tanaman dari kelompok Graminae/Poaceae yaitu padi, jagung, sorgum, tebu, alang-alang, dan berbagai jenis rumput.

Fase yang banyak ditemukan Ordo Orthoptera adalah fase V6-V10, V3-V5, dan V11-V16. Hal ini disebabkan karena pada fase-fase tersebut tanaman sedang dalam masa pertumbuhan yang pesat sehingga ketersediaan bahan makanan bagi Ordo Orthoptera juga melimpah. Menurut Sudjana, et al. (1991), unsur-unsur hara banyak diserap tanaman pada fase-fase tersebut untuk memulai pertumbuhan bakal bunga jantan (tassel) dan perkembangan tongkol. Fase V6-V10, V3-V5, dan V11-V16 juga masuk dalam fase vegetatif tanaman jagung. Tanaman Jagung pada fase vegetatif mengalami perkembangan akar, daun, dan batang baru sebelum keluarnya bunga betina dan jantan. Menurut Erawati dkk. (2004), Orthoptera menyukai daun-daun yang masih muda dengan tekstur yang belum keras. Ordo Orthoptera paling sedikit ditemukan pada fase matang fisiologis yang merupakan fase akhir dari tanaman jagung dengan kondisi tanaman yang kurang disukai oleh Orthoptera khususnya bagian daun tanaman jagung yang keras, kering, dan kadar airnya sedikit (Irham, dkk., 2015). Selain faktor morfologi yaitu mulai mengerasnya bagian daun sebagai makanan utama herbivora, pada fase ini petani juga melakukan penyemprotan pestisida untuk mengurangi serangan hama terhadap calon buah jagung. Menurut Oka (2005), salah satu faktor yang mengatur kepadatan suatu populasi serangga adalah adanya perubahan lingkungan akibat zat kimia yang sengaja diberikan pada lingkungan tersebut.

\section{SIMPULAN}

Ordo Orthoptera yang ditemukan adalah sebanyak 242 individu yang mencakup 8 famili dengan 25 jenis. Serangga Ordo Orthoptera yang ditemukan berperan sebagai omnivora, herbivora, dan predator. Famili serangga yang berperan sebagai omnivora adalah Famili Blattidae dan Grilidae, famili yang berperan sebagai herbivora adalah Pyrgomorphidae, Acrididae, Tettigonidae, Eumastacidae, dan Tetrigidae, sedangkan famili yang berperan sebagai predator adalah Famili Mantidae.

\section{UCAPAN TERIMA KASIH}

Ucapan terimakasih kepada seluruh pihak yang telah membantu dalam penelitian ini terutama kepada Drs. Joko Wiryatno, M. Si., Dr. Drs. Anak Agung Ketut Darmadi, M. Si., dan Dr. I ketut Ginantra, S. Pd. M. Si., atas kritik dan saran yang membangun dalam penulisan ini.

\section{KEPUSTAKAAN}

Akil, M., dan A. D. Hadijah, 2007. Budidaya Jagung dan Desiminasi Teknologi. Pusat Penelitian Tanam dan Pangan. Bogor.

Awmack, C. S dan S. R. Leather. 2002. Host Plant Quality and Facundity in Herbivorous Insects. Annual Review of Entomology. 47(2): 817-844.

Baco, D., dan J. Tandiabang. 1998. Hama Utama Jagung dan Pengendaliannya. Balai Penelitian Tanaman Pangan Maros. Sulawesi Selatan.

Baldi, A., anddan T. Kisbenedek. 1997. Orthopteran Assemblages as Indicators Of Grassland Naturalness in Hungary. Agriculture, Ecosystems and Environment. 66(3): 121-129.

Borror, D. J., C. A. Triplehorn, and N. F. Johnson. 1989. An Introduction to the Study of Insects 7th edition. Saunders College Publishing. New York.

1992. Pengenalan Pelajaran Serangga. Edisi Keenam. Gadjah Mada University Press. Yogyakarta. 
Buchori, D dan B, sahari. 2000. Keanekaragaman Serangga dan Pengendalian Hayati: Antara Pertanian dan Konservasi Alam. Prosiding simposium: Keanekaragaman Hayati Arthropoda pada Sistem Produksi Pertanian.

Erawati, N.V., T. Atmowidi, dan S. Kahono. 2004. Keanekaragaman dan Kelimpahan Orthopteran (Insecta) di Gunung Kendeng dan Gunung Botol, Taman Nasional Gunung Halimun, Jawa Barat, Indonesia. Berita Biologi. 7(1): 7-15.

Foltz, J. L., and Frank, J., H. 1997. Classical Biological Control of Pest Insect of Trees in the Southern United. University of Minnesota. USA

Gulo, S. A., D. Bakti, dan F. Zahara. 2014. Keanekaragaman Jenis Serangga pada Beberapa Varietas Jagung Hibrida dan Jagung Transgenik. Jurnal Online Agroekoteknologi. 2(4): 13471358 .

Hadi, M., dan Aminah. 2012. Keragaman Serangga dan Perannya di Ekosistem Sawah. Jurnal Sains dan Matematika. 20(3): 54-57.

Hastuti, D. 2012. Serangga Herbivora Yang Berasosiasi pada Tanaman Jagung dengan Jenis Pupuk Berbeda. Agroteknologi. 4(1): 15-21.

Hill. D. S. 1997. The Economic Importance of Insects. Chapman and Hal. London.

Irham F., Delima E. M., Indah A. P. R. 2015. Diversitas Serangga Ordo Orthoptera pada Lahan Gambut di Kecamatan Lalan Kabupaten Musi Banyuasin. Bioilmi. 1 (1): 1-7.

Kartasapoetra, AG. 1993. Hama Tanaman Pangan dan Perkebunan. Bumi Aksara. Jakarta.

Krebs, J. C. 1989. Ecologycal Methodology. Harper Collins Publisher.

Leatemia, J. A., dan R.Y. Rumthe. 2011. Studi Kerusakan Akibat Serangan Hama pada Tanaman Pangan di Kecamatan Bula, Kabupaten Seram Bagian Timur, Propinsi Maluku. Jurnal Agroforestri. 6(1):52-56.

Micheneau, C., J. Fournel, B. H. Warren, S. Hugel, A. Gauvin, T. P. D. Strasberg, and M. W. Chase. 2010. Orthoptera, A New Order of Pollinator. Ann Bot. 105(3): 355-364.

Oka, I. N. 2005. Pengendalian hama Terpadu dan Implementasinya di Indonesia. Gadjah Mada University Press. Yogyakarta.

Pabbage, M.S., A.M. Adnan, dan N. Nonci. 2000. Pengelolaan Hama Prapanen Jagung. Balai Penelitian Tanaman Serealia Maros. Sulawesi Selatan.

Semangun, H. 1991. Serangga. Gadjah Mada Press. Yogyakarta.
Sudjana, A., A. Rifin, dan M. Sudjadi. 1991. Jagung. Balai Penelitian Tanaman Pangan. Bogor.

Surtikanti. 2011. Hama dan Penyakit Penting Tanaman Jagung dan Pengendaliannya. Seminar Nasional Serealia. Balai Penelitian Tanaman Serealia Maros.

Susniahti, N., H. Sumeno, dan Sudrajat. 2005. Ilmu Hama Tumbuhan. Universitas Padjadjaran. Bandung.

Winarno, F. G. 1997. Kimia Pangan dan Gizi. PT. Gramedia Pustaka Utama. Jakarta. 